\title{
Perancangan Aplikasi Augmented Reality Untuk Pengenalan Ruangan Menggunakan Marker 3D Objects Tracking
}

\author{
Chaulina Alfianti Oktavia ${ }^{1}$, Rosandi Fila Setiawan ${ }^{2}$, Andrew Christianto ${ }^{3}$ \\ ${ }_{1,2,3}$ STIKI Malang \\ 1Chaulina@ stiki.ac.id, ${ }^{2} 161111031 @$ mhs.stiki.ac.id, ${ }^{3} 161111018 @$ mhs.stiki.ac.id
}

\begin{abstract}
ABSTRAK. Aplikasi mobile berbasis android tentang pengenalan ruangan adalah aplikasi yang digunakan untuk memberikan informasi kepada pengguna tentang letak-letak ruangan yang ada di Kampus STIKI Malang. Aplikasi ini merupakan aplikasi mobile berbasis teknologi Augmented Reality (AR)yang dibangun di atas platform Unity, dengan menggunakan Blender dalam desainnya.Dalam pengenalan letak ruangan, aplikasi ini memanfaatkan kamera yang ada di Smartphone yang telah terintegrasi dengan aplikasi Unity, dengan tujuan memunculkan objek ruangan untuk bagian yang telah disorot kamera di area tertentu.
\end{abstract}

Kata Kunci: JITIKA; Augmented Reality; Pengembangan Aplikasi;

ABSTRACT. Android-based mobile application about room recognition is an application that is used to provide information to users about the location of the rooms on the STIKI Malang. This application is a mobile application based on Augmented Reality (AR) technology that is built on the Unity platform, using Blender in its design. In the introduction of room location, this application utilizes existing cameras on Smartphones that have been integrated with Unity applications, with the aim of bringing up objects for the part that the camera has highlighted in a certain area.

Keywords: JITIKA; Augmented Reality; Development Application;

\section{PENDAHULUAN}

\subsection{Latar Belakang}

Perkembangan teknologi yang pesat di zaman ini membawa dampak yang signifikan untuk berbagai jenis teknologi dan penemuan baru sebagai solusi untuk mengatasi berbagai permasalahan kehidupan. Hal inilah yang mendorong manusia membutuhkan sebuah media yang dapat digunakan untuk menyelesaikan masalah dengan cepat dan efisien. Salah satu contohnya adalah media untuk memperkenalkan Augmented Reality kepada mahasiswa-mahasiswi sekarang. Alternatif penggunaan Augmented Reality bagi mahasiswamahasiswi sekarang yaitu dengan mengimplementasikan aplikasi yang dapat menunjukkan denah ruangan kelas di kampus. Aplikasi ini bertujuan membantu mahasiswa baru agar lebih mengetahui letak ruangan kelas saat pertama kali masuk kampus.

Augmented Reality dapat diterapkan pada aplikasi perangkat mobile android karena sistem pada Augmented Reality menganalisa secara realtime obyek yang ditangkap dalam kamera yang bisa diimplementasikan pada perangkat yang memiliki GPS, akselerometer, kompas, dan kamera. Menurut Mulyadi dalam Putra (2011), Android merupakan platform lengkap mulaidari sistem operasi, aplikasi, tool developing, marketapplication, dukunganvendorindustri mobile, bahkandukungan dari komunitas open system.Tentu ini merupakan keunggulan yang tidak dimiliki oleh platform lain.Dengan melihat perkembangan saat ini, android telah menjadi kekuatan yang luar biasa.Pada tahun2009,dilaporkan olehcanalys estimates, pasar smartphone untuk android tumbuh 1073,5\% disaat platform lain tidak ada yang mencapai pertumbuhan $100 \%$.

Maka pada Perancangan Aplikasi Augmtented Reality Untuk Pengenalan Ruangan Menggunakan Marker3D Objects Tracking ini bisa tempat untuk mahasiswa baru dapat mengetahui letak ruangan-ruangan yang ada di kampus, dengan begitu mahasiswa baru tidak lagi kesulitan untuk mengetahui letak ruangan ruangan yang ada di kampus dan memudahkan mereka, dan juga dalam perancangan aplikasi ini terdapat beberapa kekurangan yang harus diperhatikan yaitu pada desain $3 D$ Objects, intensitas cahaya dalam hal ini berkaitan dengan keberhasilan memunculkan objek virtual. Oleh karena itu berdasarkan pada perancangan ini akan diimplementasikan metode Marker $3 D$ Objects.

\subsection{Masalah Dan Wawasan Rencana Pemecahan Masalah}

\subsubsection{Rumusan Masalah}

Berdasarkan latar belakang di atas rumusan masalah yang dapat disimpulkan sebagai berikut :

1) Bagaimana merancang aplikasi Augmtented Reality Untuk Pengenalan Ruangan Menggunakan Marker $3 D$ Objects Tracking yang dapat membantu pengguna sebagai alat pembantu untuk memberikan informasi tentang letak ruangan- ruangan yang ada di kampus. 


\subsubsection{Batasan Masalah}

Adapun batasan masalah dalam aplikasi ini diantaranya :

1) Objek yang dimunculkan oleh kamera Augmented Reality ini bersifat statis.

2) Aplikasi ini tidak bisa digunakan oleh semua orang karena belum ditahap pengembangan aplikasi selanjutnya.

\subsection{Tujuan Penelitian}

Tujuan dari penelitian ini adalah:

1) Untuk mengetahui apa itu Augmented Reality.

2) Untuk mengetahui bagaimana cara kerja Augmented Reality.

3) Untuk membantu mahasiswa baru menemukan ruangan kelas di STIKI menggunakan Augmented Reality.

\section{METODE PENELITIAN}

\subsection{Rancangan Penelitian}

\subsubsection{Alat Dan Bahan Penelitian}

Alat yang digunakan untuk penelitian ini terdiri dari :

1. Hardware :

1) Laptop Asus A456UR.

2) Smartphone Asus.

2. Software :

1) Operating SystemWindows 10 Home.

2) Unity 3D.

3) Blender.

Bahan yang digunakan untuk penelitian ini :

1. Kelas - kelas yang ada di STIKI Malang.

2. Ruangan dosen yang ada di STIKI Malang.

\subsection{Sumber Data}

\subsubsection{Teknik Pengumpulan Data}

Teknik Pengumpulan data yang digunakan penulis dalam penelitian ini adalah :

1. Angket atau Kuesioner

Instrumen angket atau kuesioner dalam penelitian ini menggunakan skala Likert, maka variable yang diukur dijabarkan menjadi indikator-indikator yang dapat diukur. Indikator tersebut digunakan sebagai titik tolak untuk membuat item instrumen yang berupa pertanyaan atau pernyataan yang perlu dijawab oleh responden. Setiap jawaban dihubungkan dengan bentuk pernyataan atau dukungan sikap yang diungkapan dengan memberi tanda pada pilihan jawaban yang terdiri dari, Sangat Mengetahui (SM), Kurang Mengetahui (KM), Tidak Mengetahui (TM).

2. Studi Literatur

Yaitu melalui berbagai artikel yang didapat di internet dan buku-buku referensi yang menunjang pembuatan rancangan aplikasi ini.

\subsubsection{Analisis Data}

Pada tahap ini akan menganalisa hasil dari survei yang dilakukan untuk mengetahui data yang dihasilkan. Survey telah dilakukan oleh 24 responden mahasiswa baru STIKI dengan diberikan 4 pertanyaan menggunakan parameter $(\mathrm{Ya}=3$, Kurang Tahu $=2$, Tidak $=1$, Tidak menjawab =0) yang berkaitan dengan aplikasi Augmtented Reality Untuk Pengenalan Ruangan Menggunakan Marker 3D Objects Tracking menghasilkan hasil pada Tabel 1. 
Tabel 1. Hasil data Survey

\begin{tabular}{|c|c|c|c|c|c|}
\hline \multirow[b]{2}{*}{ Responden } & \multicolumn{4}{|c|}{ Score Pertanyaan } & \multirow[b]{2}{*}{$\begin{array}{c}\text { Tingkat } \\
\text { Kepuasan }\end{array}$} \\
\hline & $\begin{array}{l}\text { Mengetahui } \\
\text { tentang AR }\end{array}$ & $\begin{array}{l}\text { Mengetahui } \\
\text { Letak } \\
\text { Ruangan }\end{array}$ & $\begin{array}{c}\text { Kesulitan } \\
\text { mengetahui } \\
\text { Letak } \\
\text { Ruangan } \\
\end{array}$ & $\begin{array}{l}\text { AR bisa } \\
\text { membantu }\end{array}$ & \\
\hline 1 & 3 & 3 & 0 & 0 & 6 \\
\hline 2 & 3 & 1 & 0 & 0 & 4 \\
\hline 3 & 3 & 2 & 0 & 0 & 5 \\
\hline 4 & 3 & 3 & 0 & 3 & 9 \\
\hline 5 & 2 & 2 & 2 & 3 & 9 \\
\hline 6 & 2 & 2 & 3 & 3 & 10 \\
\hline 7 & 3 & 3 & 2 & 2 & 10 \\
\hline 8 & 1 & 2 & 2 & 2 & 7 \\
\hline 9 & 1 & 3 & 2 & 2 & 8 \\
\hline 10 & 3 & 3 & 1 & 2 & 9 \\
\hline 11 & 2 & 2 & 2 & 3 & 9 \\
\hline 12 & 3 & 3 & 3 & 2 & 11 \\
\hline 13 & 3 & 2 & 2 & 2 & 9 \\
\hline 14 & 3 & 3 & 1 & 2 & 9 \\
\hline 15 & 2 & 2 & 2 & 3 & 9 \\
\hline 16 & 2 & 2 & 3 & 3 & 10 \\
\hline 17 & 1 & 2 & 2 & 2 & 7 \\
\hline 18 & 2 & 3 & 3 & 2 & 10 \\
\hline 19 & 2 & 3 & 3 & 2 & 10 \\
\hline 20 & 2 & 3 & 2 & 2 & 9 \\
\hline 21 & 1 & 2 & 1 & 2 & 6 \\
\hline 22 & 1 & 1 & 3 & 2 & 7 \\
\hline 23 & 2 & 1 & 2 & 3 & 8 \\
\hline 24 & 2 & 3 & 2 & 1 & 8 \\
\hline
\end{tabular}

Dari Tabel 1.tersebut kita mendapatkan tingkat kepuasan dari masing - masing responden, maka jumlah tingkat kepuasan tersebut kita olah dengan menggunakan metode Korelasi dan menghasilkan data sebagai berikut :

Tabel 2. Hasil data Survey dengan Metode Korelasi

\begin{tabular}{|c|c|c|c|c|}
\hline Null & $\begin{array}{c}\text { Mengetahui } \\
\text { tentang AR }\end{array}$ & $\begin{array}{c}\text { Mengetahui } \\
\text { Letak } \\
\text { Ruangan }\end{array}$ & $\begin{array}{c}\text { Kesulitan } \\
\text { mengetahui } \\
\text { Letak } \\
\text { Ruangan }\end{array}$ & $\begin{array}{c}\text { AR bisa } \\
\text { membantu }\end{array}$ \\
\hline $\begin{array}{c}\text { Mengetahui } \\
\text { tentang AR }\end{array}$ & 1 & 0 & 0 & 0 \\
\hline $\begin{array}{c}\text { Mengetahui } \\
\text { Letak } \\
\text { Ruangan }\end{array}$ & 0,29827938 & 1 & 0 & 0 \\
\hline $\begin{array}{c}\text { Kesulitan } \\
\text { mengetahui } \\
\text { Letak }\end{array}$ & $-0,456927356$ & $-0,020228869$ & 1 & 0 \\
\hline
\end{tabular}




\begin{tabular}{|c|c|c|c|c|} 
Ruangan & & & & \\
\hline $\begin{array}{c}\text { AR bisa } \\
\text { membantu }\end{array}$ & $-0,306186218$ & $-0,066421116$ & 0,548198631 & 1 \\
\hline
\end{tabular}

Survey yang telah dilakukan untuk mendapatkan hasil data yang diperoleh dari penyebaran survey kepada mahasiswa baru STIKI. Pada hasil survey yang dilakukan dapat disimpulkan bahwa dengan parameter (Nilai >0) :

1. Pengetahuan mahasiswa baru tentang Augmented Reality mempunyai korelasi dengan pengetahuan mahasiswa baru terhadap letak ruangan-ruangan yang ada di kampus STIKI tersebut.

2. Mahasiswa baru yang mempunyai kesulitan dalam mengetahui letak ruanganruangan yang ada di kampus STIKI bisa menggunakan teknologi Augmented Reality untuk membantu mengetahui letak ruangan-ruangan yang ada di kampus STIKI.

\section{HASIL DAN PEMBAHASAN}

Augmented Reality (AR) merupakan bagian dari Environment Reality (ER) atau yang lebih dikenal sebagai Virtual Reality (VR) .Augmented Reality (AR) merupakan teknologi yang menggabungkan benda maya dua dimensi dan ataupun tiga dimensi ke dalam sebuah lingkungan nyata lalu meproyeksikan benda-benda maya tersebut dalam waktu nyata. Benda-benda maya berfungsi menampilkan informasi yang tidak dapat diterima oleh manusia secara langsung. Hal ini membuat realitas tertambah berguna sebagai alat untuk membantu persepsi dan interaksi penggunanya dengan dunia nyata. Informasi yang ditampilkan oleh benda maya membantu pengguna melaksanakan kegiatan-kegiatan dalam dunia nyata.

\subsection{Metode Marker-Based AR}

Metode marker berdasarkan dari teknologi Augmented Reality dihadirkan dari gabungan teknologi computervision dan image processing yang mencari informasi dari sebuah gambar secara langsung. Dimana marker yang didesain secara khusus, dibutuhkan untuk dihadirkan setelah proses tracking dan positioning dilakukan.

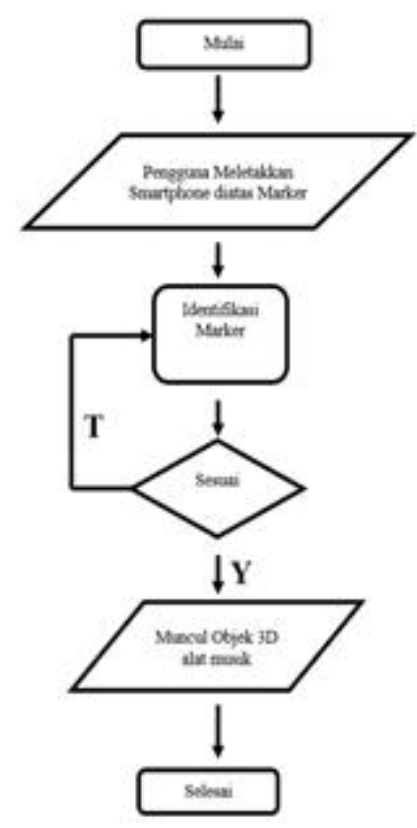

Gambar 1. FlowChart dalam aplikasi Augmented Reality 


\subsection{Tracking Marker}

Tracking marker merupakan proses yang dilakukan oleh sitem ketika melakukan pemindaian gambar terhadap database yang sudah ada. Dalam hal ini Vuforia sebagai penyedia layanan melakukan proses tracking marker dengan computer vision, dimana pada computer vision setiap gerakan dianalisa dengan mengekstraksi gambar, dan pada proses ekstraksi tersebut Vuforia menggunakan metode NFT (Natural FeatureTracking). NFT merupakan proses mendeteksi keberadaan marker dengan melihat semua fiturnya.

\subsection{Vuforia SDK}

Vuforia adalah Augmented Reality Software Development Kit(SDK) untuk perangkat mobile yang memungkinkan pembuatan aplikasi Augmented Reality. SDK Vuforia juga tersedia untuk digabungkan dengan unity yaitu bernama Vuforia Augmented RealityExtension for Unity. Vuforia merupakan SDK yang disediakan oleh Qualcomm untuk membantu para pengembang membuat aplikasi-aplikasi Augmented Reality(AR) di telepon genggam (iOS, Android). SDK Vuforia sudah sukses dipakai di beberapa aplikasi-aplikasi telepon genggam untuk kedua platform tersebut.

Augmented Reality Vuforia memberikan cara berinteraksi yang memanfaatkan kamera mobile phones untuk digunakan sebagai perangkat masukan, sebagai mata elektronik yang mengenali penanda tertentu, sehingga di layar bisa ditampilkan perpaduan antara dunia nyata dan dunia yang digambar oleh aplikasi. Dengan kata lain, Vuforia adalah SDK untuk computer vision based Augmented Reality. Jenis aplikasi Augmented Reality yang lain adalah GPS berdasarkan Augmented Reality.

\subsection{Unity 3D}

Unity merupakan suatu aplikasi yang digunakan untuk mengembangkan game multi platform yang didesain untuk mudah digunakan. Unity itu bagus dan penuh perpaduan dengan aplikasi yang profesional. Editor pada Unity dibuat dengan antarmuka pengguna yang sederhana. Editor ini dibuat setelah ribuan jam yang mana telah dihabiskan untuk membuatnya menjadi nomor satu dalam urutan peringkat teratas untuk editor game. Grafis pada unity dibuat dengan grafis tingkat tinggi untuk OpenGL dan directX. Unity mendukung semua format file, terutamanya format umum seperti semua format dari art applications. Unity cocok dengan versi 64-bit dan dapat beroperasi pada Mac OS x dan windows dan dapat menghasilkan game untuk Mac, Windows, Wii, iPhone, iPad dan Android.

Unity ini adalah sebuah aplikasi berbasis multi platform, Apa itu multi platform? Multi Platform merupakan aplikasi yang dapat beroperasi di banyak sistem operasi dan sanggup menerbitkan ke banyak format tipe file, misalnya : exe, apk,dan lain-lain.

\section{IMPLEMENTASI APLIKASI}

\subsubsection{Rancangan Konsep Kerja Aplikasi}

Rancangan konsep menentukan rencana kerja aplikasi sesuai dengan tujuan pembuatan aplikasi. Sebelum masuk ke pembahasan lebih lanjut, ada beberapa hal yang harus diketahui mengenai aplikasi yang sedang di rancang yaitu :

1) Aplikasi bersifat mobile, artinya aplikasi pengenalan ruangan ini bisa dirancang kapanpun dan dimanapun sesuai dengan kebutuhan. Hal ini terkait dengan platform implementasi aplikasi, yaitu pada smartphone.

2) Terbatas pada smartphone tertentu, aplikasi ini hanya dapat berjalan pada smartphone yang mengimplementasikan OS Android dan penggunaan kamera pada device tersebut.

Untuk lebih jelasnya mengenai cara kerja aplikasi akan dijelaskan sebagai berikut :

1) Aplikasi sudah disertai petunjuk ruangan - ruangan yang akan dituju sehingga pengguna bisa langsung mengetahui lokasi ruangan yang akan dituju dan lebih terarah.

2) Pengguna cukup memliki aplikasi tersebut, lalu bisa menggunakan aplikasi tersebut dengan menggunakan kamera guna melakukan pemindaian pada marker yang tersedia untuk mendapatkan lokasi pengguna agar bisa mengetahui letak ruangan - ruangan yang ingin dituju. 


\subsubsection{Rancangan Aplikasi}

Tahap rancangan aplikasi akan berisi rancangan aplikasi yang akan berjalan pada smartphone, dimana rancangan melalui tiga tahap yaitu penyusunan struktur menu, UML program dan rancangan antar muka.

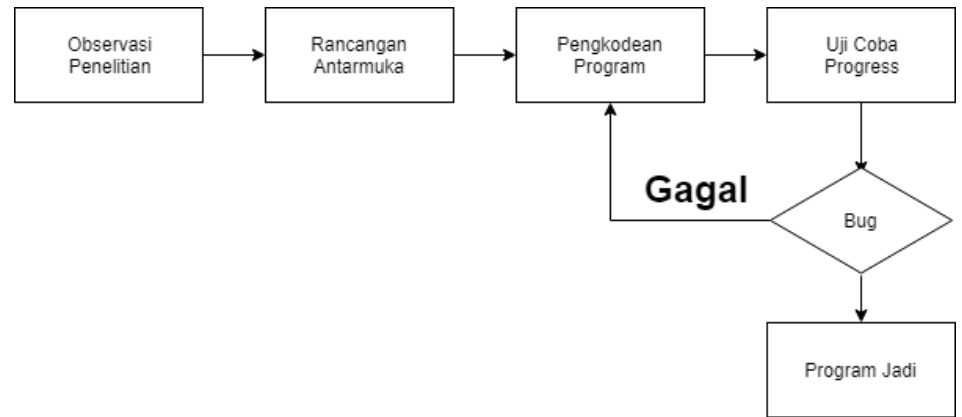

Gambar 2. Diagram Umum Proses Perancangan Aplikasi

\subsubsection{BATASAN IMPLEMENTASI}

Adapun batasan implementasi dalam proyek ini diantaranya :

1) Aplikasi ini hanya bisa menampilkan objek berdasarkan database yang ada

2) Objek yang muncul tidak bisa disentuh maupun digerakkan

\subsection{IMPLEMENTASI INTERFACE}

Pada tahap ini akan diuraikan mengenai bagaimana Augmtented Reality diimplementasikan dan juga hasil pengujiannya.

\subsubsection{DATABASE}

Pada aplikasi Augmtented Reality Untuk Pengenalan Ruangan Menggunakan Marker 3D Objects Tracking menggunakan database dengan uraian sebagai berikut :

1. Target Name, merupakan nama objek marker yang digunakan

2. Type, merupakan tipe dari objek tersebut

3. Rating, nilai kesensitifan objek marker yang digunakan

4. Status, objek marker yang aktif

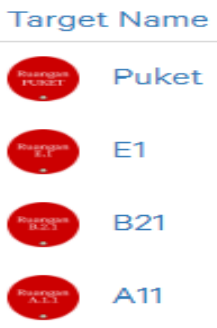

$\begin{array}{ll}\text { Type } & \text { Rating } \\ \text { Single Image } & \text { Active } \\ \text { Single Image } & \text { Active } \\ \text { Single Image } & \text { Active } \\ \text { Single Image } & \text { Active }\end{array}$

Gambar 3. Database

\subsubsection{Model 3d}

Beberapa desain $3 D$ ini yang akan muncul dari marker yang telah dilakukan scanning dari camera Augmented Reality sendiri.

(1)

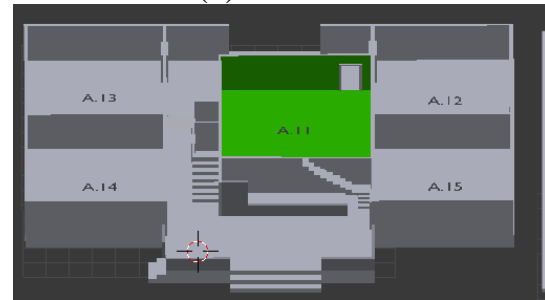

(3)
(2)

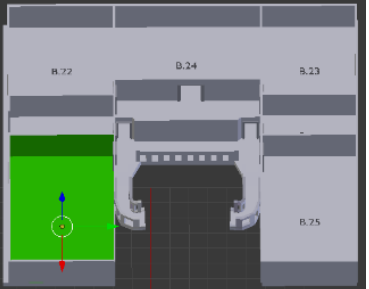

(4) 


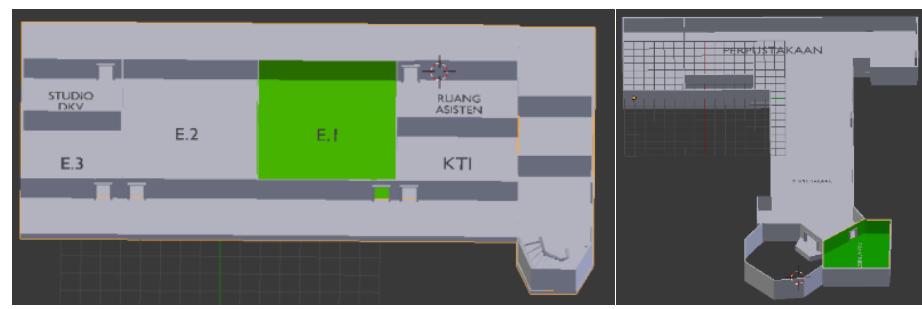

Gambar 4. Model 3D

(1) Bentuk Model $3 D$ yang berbentuk Ruangan A.1.1

(2) Bentuk Model $3 D$ yang berbentuk Ruangan B.2.1

(3) Bentuk Model $3 D$ yang berbentuk Ruangan E.1

(4) Bentuk Model $3 D$ yang berbentuk Ruangan Puket

\subsubsection{Marker}

Beberapa marker ini yang akan digunakan untuk tempat pengguna melakukan scanning yang akan memunculkan objek dari camera Augmented Reality sendiri.

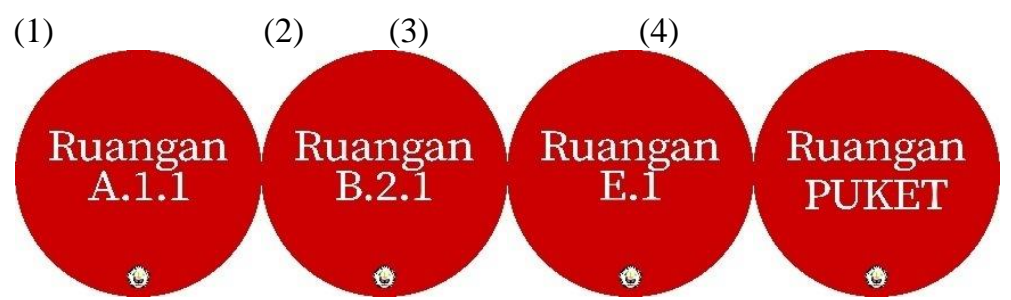

Gambar 5. Marker Augmented Reality

(1) Marker yang bertulisan "Ruangan A.1.1" akan memunculkan objek ruangan A.1.1

(2) Marker yang bertulisan "Ruangan B.2.1" akan memunculkan objek ruangan B.2.1

(3) Marker yang bertulisan "Ruangan E.1" akan memunculkan objek ruangan E.1

(4) Marker yang bertulisan "Ruangan Puket" akan memunculkan objek ruangan Puket

\subsubsection{Tampilan Alur Halaman Aplikasi}

Terdapat tiga halaman pada aplikasi Augmented Reality seperti yang dapat dilihat pada Gambar.

(1)

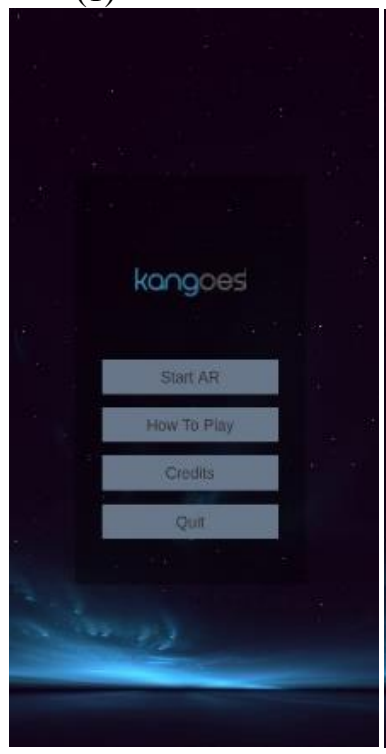

(2)

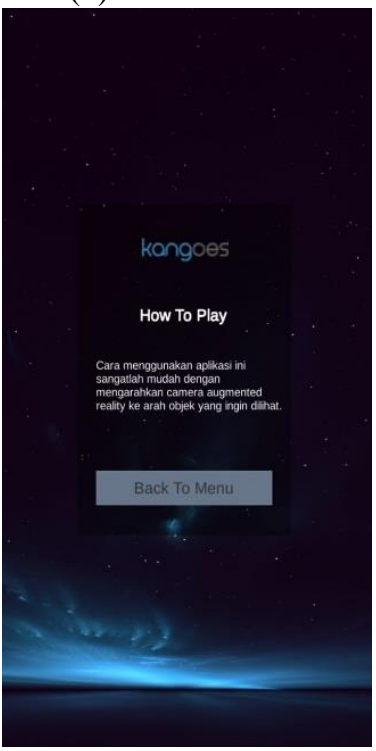

(3)

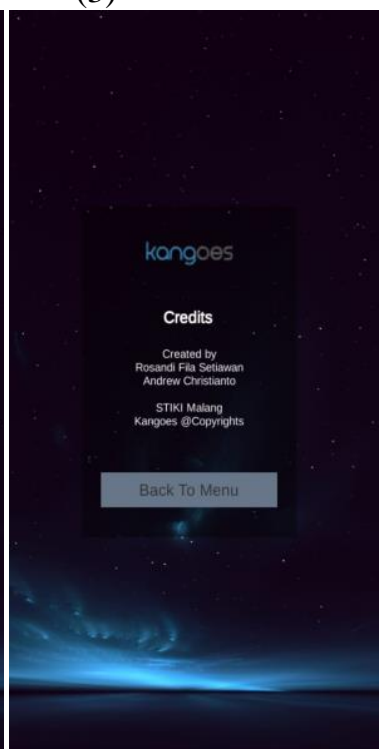

Gambar 6. Tampilan Alur Halaman Aplikasi 
(1) Pada Main Menu Screen terdapat logo dari aplikasi dan terdapat menu - menu yang saat pengguna menyentuh menu tersebut maka penggunadiarahkan pada menu selanjutnya.

(2) Pada How To Playterdapat logo dari aplikasi dan terdapat penjelasan cara menggunakan aplikasi ini dan terdapat menu Back to Menu untuk kembali pada Main Menu.

(3) Pada credits terdapat logo dari aplikasi dan terdapat informasi tentang aplikasi tersebut dan terdapat menu Back to Menu untuk kembali pada Main Menu.

\section{KESIMPULAN DAN SARAN}

\subsection{Kesimpulan}

Berdasarkan penelitian di atas dapat diambil kesimpulan bahwa dalam pencarian ruangan pada kampus STIKI dapat digunakan melalui kamera dengan menggunakan teknologi Augmented Reality dan dalam aplikasi pencarian ruangan pada kampus STIKI memudahkan pengguna dalam mencari informasi letak-letak ruangan kelas dengan begitu teknologi Augmented Reality dapat berfungsi dalam penerapan pencarian letak ruangan kelas.

\subsection{Saran}

Penulis menyadari dalam pembuatan aplikasi Augmented Reality ini terdapat banyak kekurangan yang dapat diperbaiki, maupun dilengkapi oleh pengembang selanjutnya. Adapun kekurangan dari aplikasi ini seperti berikut:

1. Pengembang aplikasi Augmented Reality dapat melakukan pengembangan terhadap pembuatan objek $3 D$ agar menyerupai objek sesungguhnya dengan ukuran file yag kecil agar aplikasi tidak berukuran besar.

2. Pengembang disarankan menambahkan fitur-fitur yang dibutuhkan ke dalam aplikasi Augmented Reality

3. Pengembang disarankan dapat lebih mengoptimalkan aplikasi yang mirip

\section{TINDAK LANJUT}

Dalam pembuatan jurnal aplikasi Augmtented Reality Untuk Pengenalan Ruangan Menggunakan Marker 3D Objects Tracking akan dilakukan pengembangan aplikasi yang lebih mendalam terhadap sistem aplikasi ini terkait masalah- masalah teknis yang terjadi sewaktu - waktu di luar kendali pengembang maupun penulis, seperti objek yang tidak muncul maupun bentuk objek yang berantakan dalam proses scanning. Tampilan aplikasi yang monoton ini semoga menjadi acuan pengembang untuk mengembangkan aplikasi ini yang memungkinkan pengguna untuk bisa menggunakan aplikasi ini dengannya dan tanpa kendala dan tampilan yang menarik untuk kelanjutannya.

\section{DAFTAR RUJUKAN}

[1]BPS. (2016, Mei 20). Jumlah Penduduk dan Laju Pertumbuhan Penduduk Menurut Kabupaten/Kota di Provinsi Jawa Timur, 2010, 2014, dan 2015. Retrieved from Badan Pusat Statistik Provinsi Jawa Timur:http://jatim.bps.go.id

[2]Fuhrt, B. (2011). Handbook of Augmented Reality. New York: Spronger..

[3]Govillkar, S., \& Amin, D. (2015). Comparative(E, 2011)Study of Augmented Reality SKD's. InternationalJournal on Coputational Sciences \& Application (IJCSA), 2-7.

[4]Katiyar, A., Kalra, K., \& Grag, C. (2015). Marker Based Augmented Reality. Advance in COmputer Science and Information Technology, vol 2.

[5]Munzi, G. G. (2014). Penerapan Augmented Reality Pada Brosur Mobil Dengan Platform Android Di Toyota Auto 2000 Bandung. Makalah Seminar Tugas Akhir.

[6]Septria, E. (2011). Augmented Reality Panduan Belajar Sholat berdasarkan Buku Teks Belajar Sholat Menggunakan Android. Jurnal Teknik Informatika. Universitas Gunadarma.

[7]Bonafix, Dominicus Nunnun. 2005. Animasi 3D profesional dengan maya. Jakarta: Elex Media Komputido.

[8] Rahman, Abdur. Dkk. 2014. Rancang Bangun Aplikasi Informasi Universitas Bengkulu Sebagai Panduan Pengenalan Kampus Menggunakan Metode Markerless Augmented Reality Berbasis Android.

[9]Br,Ginting, S. L., \& Hidayat, E. S. (t.thn.). Penerapan Teknologi Augmented Reality SebagaiMedia

[10]Pengenalan Gedung Baru Unikom Berbasis Android. Majalah Ilmiah UNIKOM, 283-296. Katiyar, A., Kalra, K., \& Garg, C. (2015). Marker Based Augmented Reality. Advances in Computer Science and Information Technology, 2.

[11]Edward, Jhon. 2014. Visualisasi Lingkungan Kampus Politeknik Negeri Batam Menggunakan Augmented Reality. 